\title{
Wnt/ $\beta$-catenin signaling pathway is involved in induction of apoptosis by oridonin in colon cancer COLO205 cells
}

\author{
Heqi Bu ${ }^{1 \#}$, Dianlei Liu ${ }^{2 \#}$, Junhui Cui ${ }^{1}$, Ke Cai ${ }^{1}$, Feng Shen ${ }^{1}$ \\ ${ }^{1}$ Department of Coloproctological Surgery, Tongde Hospital of Zhejiang Province, Hangzhou 310012, China; ${ }^{2}$ Department of Surgery, Women's \\ Hospital School of Medical Zhejiang University, Hangzhou 310006, China \\ \#These authors contributed equally to this work. \\ Contributions: (I) Conception and design: All authors; (II) Administrative support: J Cui; (III) Provision of study materials or patients: D Liu; (IV) \\ Collection and assembly of data: K Cai, F Shen; (V) Data analysis and interpretation: H Bu, D Liu; (VI) Manuscript writing: All authors; (VII) Final \\ approval of manuscript: All authors. \\ Correspondence to: Feng Shen. Department of Coloproctological Surgery, Tongde Hospital of Zhejiang Province, 234 Gu-Cui Road, Hangzhou \\ 310012, China. Email: tdshenfeng@163.com.
}

Background: Oridonin has been demonstrated to have anticancer effect on all kinds of cancer cells and it has shown anti-tumor activity in some tumors partially via the inactivation of $\mathrm{Wnt} / \beta$-catenin signaling pathway. The study investigated the anticancer effect of oridonin on colon carcinoma cell line COLO205 and explored underlying mechanism.

Methods: Cell Counting Kit-8 (CCK-8) assay was performed to assess cell viability. Flow cytometry was performed to analyze the apoptosis. The key target genes and proteins involved in $\mathrm{Wnt} / \beta$-catenin pathway were detected by quantitative polymerase chain reaction (qPCR) and Western blotting. The xenograft tumor model of colon cancer COLO205 cell was introduced to detect anti-tumor effects in vivo. Transferasemediated dUTP nick end labeling (TUNEL) assay was adopted to test the apoptotic cells in the tumor tissues.

Results: Oridonin inhibited the proliferation of colon cancer COLO205 cells in a dose-dependent and time-dependent manner. Oridonin induced apoptosis by increasing the cleavage of caspases in vitro. Furthermore, the expression levels of $\beta$-catenin and its downstream targets, including c-myc, cyclinD1 and survivin were significantly reduced. Nevertheless the knockdown of $\beta$-catenin by specific small interfering RNA (siRNA) could augment the anti-proliferative and pro-apoptotic effects by oridonin in COLO205 cells. Meanwhile, oridonin also increased protein expression level of glycogen synthase kinase $3 \beta$ (GSK3 $\beta$ ) and decreased the phosphorylation level of GSK3 $\beta$. In vivo, oridonin treatment significantly suppressed tumor growth of COLO205 cell xenografts, and which was accompanied by the restrain of $\mathrm{Wnt} / \beta$-catenin pathway. Conclusions: Our present study demonstrated that the growth inhibition and apoptosis induction in colon cancer COLO205 cells by oridonin could be partially mediated through discontinuing Wnt/ $\beta$-catenin signaling pathway.

Keywords: Oridonin; Wnt/ $\beta$-catenin pathway; glycogen synthase kinase $3 \beta$ (GSK3 $\beta$ ); apoptosis; colon cancer

Submitted Feb 24, 2019. Accepted for publication Aug 07, 2019.

doi: $10.21037 /$ tcr.2019.08.25

View this article at: http://dx.doi.org/10.21037/tcr.2019.08.25 


\section{Introduction}

Colorectal cancer (CRC) is common worldwide, especially in the western countries. Recent statistics have showed that there are 694,000 CRC-related deaths and 1.36 million new CRC cases around the world each year (1). In China, the incidence rate of CRC ranks fifth in males and third in females, and CRC is the fifth commonly leading cause of cancer death among both sexes (2). The interaction of various factors results in the development of CRC (3). Generally speaking, surgical removal is often curative, but it only offers therapeutic possibilities for these patients at an early stage. Therefore, conventional treatments such as chemotherapy is still one of the basic methods to treat CRC. Although chemotherapy as a principal means has enhanced survival rates, it leads to many undesirable side effects. Meanwhile, growing evidence shows that CRC cells are prone to escape apoptosis due to variant clonal proliferation (4). Therefore, it is necessary to develop more efficient treatments with unequivocal mechanisms for CRC.

Studies have proved that the $\mathrm{Wnt} / \beta$-catenin pathway has vital influence on the development of CRC (5). Under normal circumstances, $\beta$-catenin is able to form a complex consisting of glycogen synthase kinase $3 \beta$ (GSK3 $\beta$ ), axis inhibition proteins (AXIN), casein kinase 1 (CK1) and adenomatous polyposis coli (APC), which is degraded due to the ubiquitination process. During CRC, when APC is mutated and the complex including AXIN, GSK3 $\beta$ and APC will dissociate, as a consequence, free $\beta$-catenin will accumulate in the cytoplasm and accumulated cytoplasmic $\beta$-catenin translocates to the nucleus (6). Whereafter, $\beta$-catenin binds with T-cell factor (TCF)/lymphoid enhancer factor (LEF) in the nucleus and finally activates transcription of Wnt downstream oncogenic target genes such as c-myc and cyclinD1, which are beneficial to cell proliferation (7). Because of these factors, it has become the crucial target for $\mathrm{Wnt} / \beta$-catenin pathway to treat CRC (8). Hence, the blocking of $\mathrm{Wnt} / \beta$-catenin pathway is significant in the search for possible antitumor drugs.

Oridonin (Figure 1A), a natural and safe ent-kaurene diterpenoid compound isolated from Rabdosia rubescens, is one of the most important active Chinese medicinal components. Previous studies have demonstrated that oridonin has multiple pharmacological and physiological activities, such as anti-inflammatory, anti-bacterial, neuroprotective and antitumor effects (9). In recent years, oridonin has attracted more attention because it presents broadspectrum anti-proliferative activity in various types of cancer both in vivo and in vitro. Recently, it has been verified that oridonin has potent inhibitory effect on human osteosarcoma cells and neurocytoma cells by inhibiting Wnt/ $\beta$-catenin signaling pathway $(10,11)$. Although reports have shown that induction of apoptosis by oridonin in CRC cells may be concerned with the activation of the bone morphogenetic protein 7 (BMP7)/mitogen activated protein kinase $\mathrm{p} 38(\mathrm{p} 38 \mathrm{MAPK}) / \mathrm{p} 53$ signaling pathway, or mediated via enhancing the function of phosphatase and tensin homologue (PTEN) through activating p38MAPK $(12,13)$. But, the relationship between the anti-tumor activity of oridonin on CRC and the $\mathrm{Wnt} / \beta$-catenin signaling pathway is rarely reported. Despite substantial evidence supports that oridonin is capable of inhibiting growth of CRC, the exact mechanism for this process is still poorly understood.

In this study, we firstly explored anti-proliferation and apoptotic induction effects of oridonin on colon cancer COLO205 cells in vitro and in vivo. Then, we demonstrated whether its possible mechanisms were mediated through Wnt/ $\beta$-catenin pathway, which would help to make full sense of the fundamental mechanisms concerned in antiCRC action. The data of our present study offer new unique opinions into the mechanism for oridonin as a chemotherapeutic drug in the treatment of CRC.

\section{Methods}

\section{Materials}

Oridonin (purity $>98 \%$ ) was acquired from Aladdin Biochemical (Beijing, China), and dissolved in $0.5 \%$ dimethyl sulfoxide (DMSO) at a stock concentration of $10 \mathrm{~m} / \mathrm{mol}$. As required for individual experiments, the stock solutions were diluted by culture medium at the work concentration. The DMSO final concentration did not exert any detectable impact on cell growth or cell death. Fetal bovine serum (FBS), Dulbecco's modified Eagle's medium (DMEM), penicillin/streptomycin, 0.25\% trypsin containing ethylenediaminetetraacetic acid (EDTA), Cell Counting Kit-8 (CCK-8) were obtained from Gibco (CA, USA); DMSO, specific GSK3 $\beta$ inhibitor lithium chloride $(\mathrm{LiCl})$ was bought from Beyotime Biotechnology (Shanghai, China). Radioimmunoprecipitation assay (RIPA) lysis buffer, Annexin V-fluorescein isothiocyanate-propidium iodide (FITC-PI) Apoptosis Detection Kit and bicinchoninic acid (BCA) Protein Assay Kit were provided by Thermo Scientific Pierce Protein Research Products (Waltham, MA, USA). mouse monoclonal antibodies against cleaved 
A

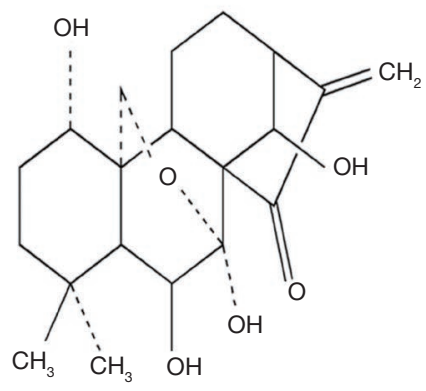

B

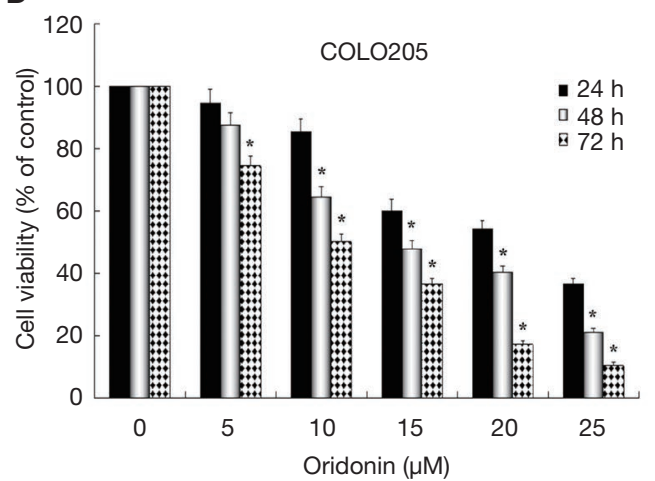

Figure 1 Effects of oridonin on the growth of colon cancer COLO205 cells. (A) Chemical structure of oridonin; (B) the COLO205 cells were treated with various doses of oridonin $(0-25 \mu \mathrm{M})$ for 24,48 or 72 h respectively. The cell viability was determined by CCK-8 assay. *, $\mathrm{P}<0.05$ (vs. the control). CCK-8, Cell Counting Kit-8.

caspase-3, cleaved poly (ADP-ribose) polymerase (PARP), glyceraldehyde 3-phosphate dehydrogenase (GAPDH) were bought from Cell Signaling Technology, Inc. (Danvers, MA, USA); mouse monoclonal anti-GSK3 $\beta$ antibody, mouse monoclonal anti-p-GSK3 $\beta$ antibody, mouse monoclonal anti- $\beta$-catenin antibody, mouse monoclonal anti-cyclinD1, c-myc and survivin antibody were obtained from SigmaAldrich (St. Louis, MO, USA); goat anti-mouse IgG-HRP secondary antibody were obtained from Beijing Transgen Biotech Co., Ltd. (Beijing, China).

\section{Cell culture}

The colon cancer COLO205 cell line was bought from enzyme Biotechnology Co., Ltd. (Shanghai, China). The cells were grown in RPMI-1640 medium containing $10 \%$ FBS and antibiotics (100 units/mL penicillin, $100 \mu \mathrm{g} / \mathrm{mL}$ streptomycin). The cells were kept in an incubator under humidified atmosphere containing $5 \% \mathrm{CO}_{2}$ at $37^{\circ} \mathrm{C}$. The medium was replaced 2-3 times a week according to the relative cell growth conditions. The cells were subcultured at $80-90 \%$ confluency of the culture plate.

\section{Cell viability assay}

Cell viability assay was analyzed by CCK- 8 kit according to the introductions with minor modifications. Briefly, $100 \mu \mathrm{L}$ cell suspension in the logarithmic phase was dispensed in 96 -well culture plates $\left(3 \times 10^{3}\right.$ per well) overnight. Then cells were treated with oridonin at different concentrations $(0,5,10,15,20,25 \mu \mathrm{M})$ and incubated for another 24,48 , or $72 \mathrm{~h}$, respectively. There were 6 wells in each group. Next, $10 \mu \mathrm{L}$ of CCK working solution was added to each well and then incubated for $1-3 \mathrm{~h}$ at $37^{\circ} \mathrm{C}$. The absorbance at $450 \mathrm{~nm}$ was read using Bio-Tek (ELX800, VT, USA).

\section{Flow cytometry analysis for apoptosis}

Annexin V-FITC/PI Apoptosis Detection Kit was used to assess cell apoptosis. Briefly, approximately $5 \times 10^{5}$ cells/well were seeded into 6-well plates and incubated overnight at $37^{\circ} \mathrm{C}$. Then cells were treated with oridonin at various concentrations $(10,15,20 \mu \mathrm{M})$ or DMSO for $48 \mathrm{~h}$, respectively. Cells were harvested, centrifuged at $1,500 \times \mathrm{g}$ for $5 \mathrm{~min}$, washed with cold PBS, and then resuspended in $0.5 \mathrm{~mL}$ of binding buffer containing Annexin V-FITC/PI. After incubation for $15 \mathrm{~min}$ at room temperature in the dark, the samples were analyzed by using a flow cytometer (Becton Dickinson, CA, USA).

\section{Western blot analysis}

The total protein was dissolved by RIPA buffer. The nuclear and cytoplasmic protein extraction kit (Sangon Biotech Co., Ltd., Shanghai, China) was used to extract the nuclear and cytoplasm proteins of COLO205 cell line according to the manufacturer's instructions. The protein concentrations were determined by the BCA Protein Assay Kit. The protein lysates ( $40 \mu \mathrm{g} / \mathrm{lane}$ ) were separated by $10 \%$ sodium dodecyl sulfate polyacrylamide gel electrophoresis (SDS-PAGE) systems and transferred onto polyvinylidene 
Table 1 Primer sequences used for RT-qPCR analysis

\begin{tabular}{|c|c|c|c|}
\hline Genes & Strand & Primer sequences & Product size (bp) \\
\hline$\beta$-catenin & Reverse & 5'-ATTTGAAGGCAGTCTGTCGTA-3' & \\
\hline \multirow[t]{2}{*}{ C-myc } & Forward & 5'-AGCGACTCTGAGGAGGAACA-3' & 250 \\
\hline & Reverse & 5'-TCCAGCAGAAGGTGATCCA-3' & \\
\hline CyclinD1 & Reverse & 5'-CAGTCCGGGTCACACTTGAT-3' & \\
\hline \multirow[t]{2}{*}{ Survivin } & Forward & 5'-ATTTTGAATCGCGGGACCC-3' & 127 \\
\hline & Reverse & 5'-GAGAAAGGGCTGCCAGGC-3' & \\
\hline GAPDH & Forward & 5'-GATGATTGGCATGGCTTT-3' & 200 \\
\hline
\end{tabular}

RT-qPCR, real-time quantitative polymerase chain reaction; GAPDH, glyceraldehyde 3-phosphate dehydrogenase.

difluoride (PVDF) membranes which were blocked with 5\% non-fat milk in Tris-buffered saline (TBS) containing $0.1 \%$ Tween-20 for $2 \mathrm{~h}$. Then, the membranes were blotted with the primary antibodies at 1:500-1:1,000 dilutions with 5\% BSA in TBST overnight at $4{ }^{\circ} \mathrm{C}$. The blots were washed and incubated with secondary antibodies $(1: 2,000)$ conjugated with horseradish peroxidase (HRP) for additional $2 \mathrm{~h}$ at room temperature. The membranes were visualized using ECL chemiluminescence agent and GAPDH was used as a control for normalization. Immunoreactivity was detected by enhanced chemiluminescent Kit (Gibco, CA, USA). Densitometric analysis for the quantification of the bands was performed using Quantity One software (Bio-Rad Laboratories, CA, USA).

\section{$R N A$ extraction and quantitative polymerase chain reaction (qPCR)}

Treated and untreated cells or tumor tissues were respectively harvested. The total RNA was extracted by the TRIzol reagent (Roche, Suisse). Then, the samples were treated with DNase I and reverse transcribed using oligo-dT primers. The total cDNA was used as starting material for real-time PCR (RT-PCR) with FastStart Universal SYBR Green Master Mix (Roche Applied Science, Germany) on a StepOne RT-PCR System (Life Technologies Corp., CA, USA). The reaction conditions were: 35 cycles at $95{ }^{\circ} \mathrm{C}$ for $30 \mathrm{~s} ; 64^{\circ} \mathrm{C}$ for $25 \mathrm{~s}$; and $72{ }^{\circ} \mathrm{C}$ for $30 \mathrm{~s}$. The specific primers reported in Table 1 were designed using gene runner software and synthesized by Beijing Aoke Biotechnology Co., Ltd.
(Beijing, China). GAPDH expression was used to normalize the $\mathrm{Cq}$ values. $\mathrm{Cq}$ value was obtained from instrument software. The relative quantification of gene expression was calculated by $2^{-\Delta \Delta C q}$ method.

\section{Small interfering RNA (siRNA)}

Duplex siRNAs were synthesized at GenePharma (Beijing, China). The target sequences were as follows: $\beta$-catenin: 5 ' - CAGGGGGUUGUGGUUAAGCUCUU - 3 '; scrambled control: 5'-TTCTCCGAACGTGTCACGT-3'. The lipofectamine 2000 (Invitrogen, San Diego, CA) was used to conduct transfection based on the instruction of manufacturer. Cells were seeded into 6-well plates and transfected when the cell density increased at a rate of $30 \%$ to $50 \%$. Briefly, the corresponding freeze-dried oligos were prepared with RNase-free water; equal amounts of oligos were diluted with $250 \mu \mathrm{L}$ serum-free MEM culture medium, which were mixed with $250 \mu \mathrm{L}$ MEM containing $5 \mu \mathrm{L}$ lipofectamine 2000 transfection regent. The $500 \mu \mathrm{L}$ mixture was mixed gently and incubated for 30 minutes at room temperature. The transfection solution was then placed into the cell plate. After $6 \mathrm{~h}$ incubation, the medium was replaced with a complete medium. And then subcultured for 48 hours, the cells were obtained for western blotting analysis and apoptosis assay.

\section{Experimental animals}

Male athymic BALB/c (nu/nu) nude mice (4-6 weeks old, 
weighting 18-20 g) were ordered from the Beijing Cancer Institute for tumor implantation. All mice were maintained in a sterile environment (temperature $23 \pm 2{ }^{\circ} \mathrm{C}$, relative humidity $60-65 \%$ and a 12 h light-dark cycle) during the entire experimental. All experimental procedures and protocols were approved by the Institutional Animal Care and Use Committee of the Zhejiang Chinese Medical University.

\section{Subcutaneous tumor xenograft model}

Briefly, $200 \mu \mathrm{L}$ the COLO205 cell $\left(1 \times 10^{7}\right.$ cells $\left./ \mathrm{mL}\right)$ suspension was subcutaneously injected into the right abdominal flank of the mice. All surgical procedures were done under sterilized conditions. Tumors were permitted to grow until a size of $100-150 \mathrm{~mm}^{3}$. Then all nude mice were randomly assigned to control group and treatment groups (6 mice/group) and numbered. Mice were respectively treated intraperitoneally (IP) with normal saline and oridonin $(10,20 \mathrm{mg} / \mathrm{kg})$ every 3 days for up to 30 days in a volume of $0.2 \mathrm{~mL}$. Mice body weight were measured by an electronic balance every week. One week after the last injection, the mice were sacrificed and the tumors were excised, harvested, weighed and analyzed. The volumes of tumors were calculated according to the following formula: tumor volume $\left(\mathrm{mm}^{3}\right)=1 / 2 \times(\text { width })^{2} \times$ (length). A part of tumors from different groups were harvested, fixed with $10 \%$ formalin and embedded with paraffin and cut into suitable sections for transferase-mediated dUTP nick end labeling (TUNEL) assay, qPCR and western blotting analysis. Western blotting analysis in tumor tissue was performed as previously described in vitro.

\section{TUNEL assay}

The apoptotic cells in the tumor tissues were detected by terminal deoxynucleotidyl TUNEL assay. In short, after tissue sections were deparaffinized and rehydrated, a one-step TUNEL cell apoptosis detection kit (Beyotime, Shanghai, China) was performed to examine the apoptosis according to the protocol outlined by the manufacturer. The results were recorded and photographed using Fluorescence Microscope (Keyence, Osaka, Japan).

\section{Statistical analysis}

The results of all experiments are presented as mean \pm standard deviation (SD) of at least three independent tests. Results were analyzed using one-way analysis of variance (ANOVA-one way) or Student's $t$-test by SPSS 18.0 software. And A statistically significant difference was considered as $\mathrm{P}<0.05$.

\section{Results}

\section{Oridonin inbibited proliferation of colon cancer cells}

We first evaluated the inhibitory effect of oridonin on cell viability in colon cancer cell line COLO205. As shown in Figure 1, Results demonstrated that the cell viability was effectively inhibited by oridonin in a concentration- and time-dependent manner. The half maximal inhibitory concentration (IC50) value of oridonin in COLO205 cells was $\sim 15-20 \mu \mathrm{M}$ at $48 \mathrm{~h}$. To investigate the potential molecular mechanism, we selected 15 and $20 \mu \mathrm{M}$ oridonin for subsequent experiments.

\section{Oridonin induced apoptosis in COLO205 cells}

To investigate whether cell growth inhibitory effect following oridonin treatment was concerned with apoptosis. Flow cytometric analysis was performed using Annexin V-FITC/PI double staining. As shown in Figure 2A,B, the apoptotic cell ratio was significantly increased following treatment with $10 \mu \mathrm{M}(23.8 \% \pm 2.7 \%), 15 \mu \mathrm{M}(43.2 \% \pm 3.2 \%)$ or $20 \mu \mathrm{M}(56.3 \% \pm 4.2 \%)$ oridonin for $48 \mathrm{~h}$ compared with the control group $(8.5 \% \pm 1.7 \%$; all $\mathrm{P}<0.05)$. Furthermore, In the light of the results of the apoptotic rate, western blotting assay was employed to test the expression of apoptosisrelated crucially proteins. Therefore, we tested the protein expression levels of cleaved caspase- 3 and cleaved PARP. After cells were treated with oridonin at different doses for $48 \mathrm{~h}$, the data exhibited that the expression of cleaved caspase- 3 and cleaved PARP were found to be evidently increased in a dose dependent manner (Figure 2C,D). The above results suggested that oridonin treatment significantly promoted apoptosis and cell proliferation inhibition by oridonin was at least partly due to apoptosis induction.

\section{Effects of oridonin on the $\beta$-catenin, $c$-myc, cyclinD1, survivin, GSK3 $\beta$ and $p-G S K 3 \beta$}

Current evidence has proved that $\mathrm{Wnt} / \beta$-catenin pathway plays a vital role in many cancers, including CRC. When the $\mathrm{Wnt} / \beta$-catenin pathway is activated, then $\beta$-catenin enters into nucleus to activate a range of target genes 
A

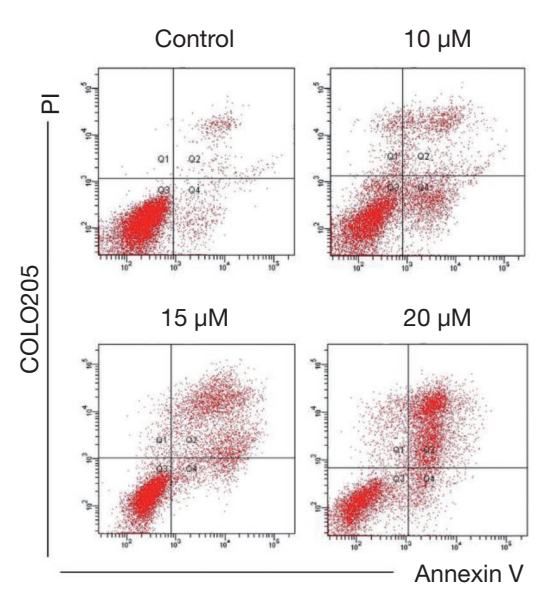

C

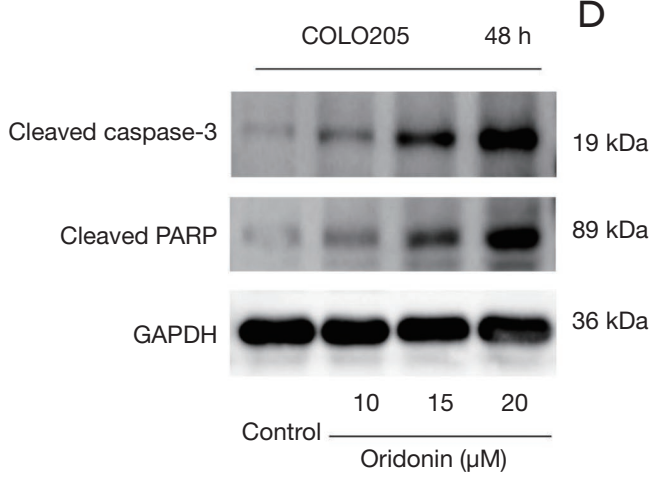

B
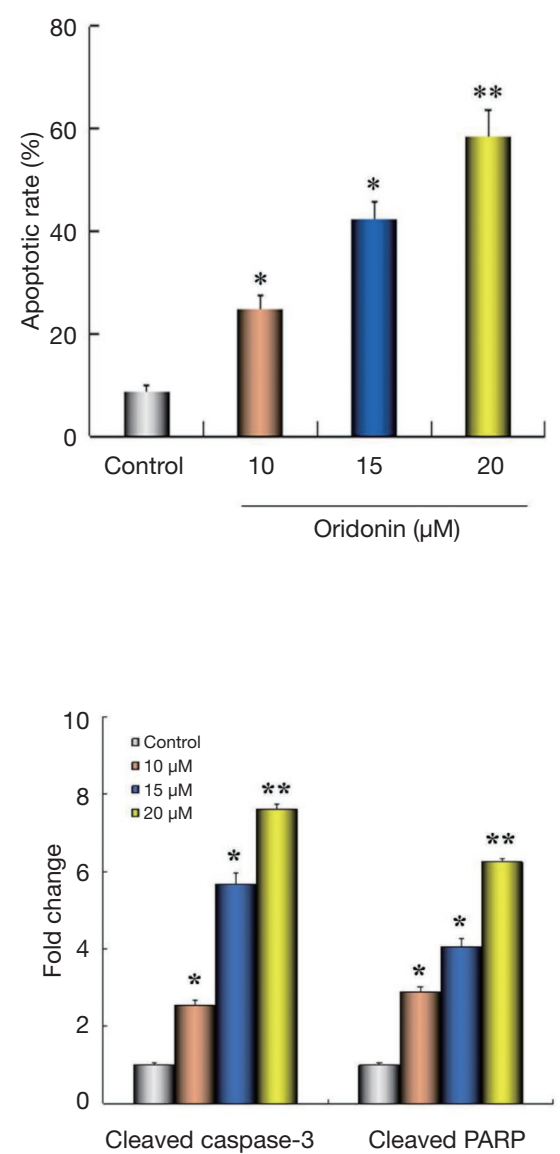

Figure 2 Effects of oridonin on apoptosis of COLO205 cells. cells were treated with oridonin (0,10,15 and $20 \mu \mathrm{M})$ for 48 h. (A) Results of flow cytometric analysis; (B) the percentage of apoptotic cells is presented as the mean $\pm \mathrm{SD}$ of three independent experiments; (C) results of western blotting analysis; (D) quantified data from the western blotting. *, $\mathrm{P}<0.05$ ( $v$. the control); **, $\mathrm{P}<0.01$ ( $v$ s. the control). SD, standard deviation; PARP, poly (ADP-ribose) polymerase; GAPDH, glyceraldehyde 3-phosphate dehydrogenase.

transcription, mainly including c-myc, cyclinD1, apoptosisassociated gene survivin. To elucidate whether Wnt/ $\beta$-catenin pathway is related to cell proliferation inhibition and apoptosis induction by oridonin. We first detected the expression levels of $\beta$-catenin, c-myc, cyclinD1 and survivin in COLO205 cells. As shown in Figure 3A, As compared with the control group, the mRNA expression level of $\beta$-catenin was markedly decreased in oridonin-treated groups. In addition, the protein expression of $\beta$-catenin at both cytoplasm and nucleus were dramatically reduced after treatment with oridonin (Figure 3B,C). Furthermore, expression of c-myc, cyclinD1 and survivin were significantly down-regulated at both mRNA and protein levels by oridonin in COLO205 cells (Figure $3 A, D, E$ ).

To further verify whether $\beta$-catenin inactivation was necessary for induction of cell apoptosis by oridonin, specific siRNA was used to silencing $\beta$-catenin. As shown in Figure 3F, G, As compared with the scramble siRNA control group, protein expression of cleaved caspase- 3 and pro-apoptotic effect were aggravated. To illuminate how oridonin affected the nuclear translocation of $\beta$-catenin, we investigated the function of upstream regulatory proteins in Wnt/ $\beta$-catenin pathway. Evidence has shown that GSK3 $\beta$ has the vital role in $W n t / \beta$-catenin signaling, and it is abnormally inactivated in the development of CRC (14). As shown in Figure 4, our results showed that a significant increase of GSK3 $\beta$ was observed after oridonin treatment and the phosphorylation of GSK3 $\beta$ was suppressed by oridonin. When in the presence of a GSK3 $\beta$ inhibitor $\mathrm{LiCl}$, oridonin-induced apoptosis, activation of cleaved PARP 


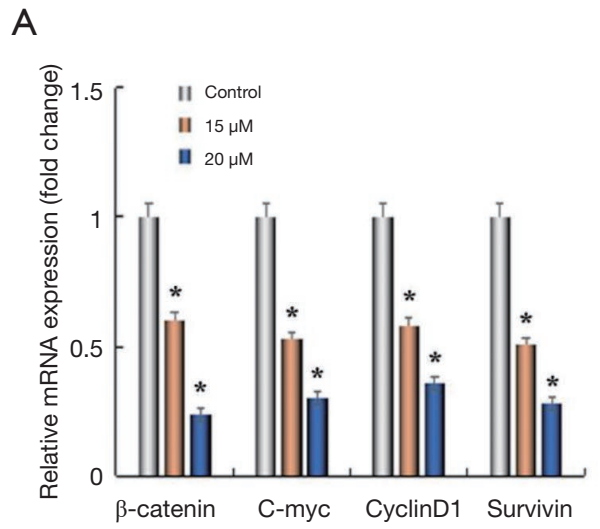

$\mathrm{D}$

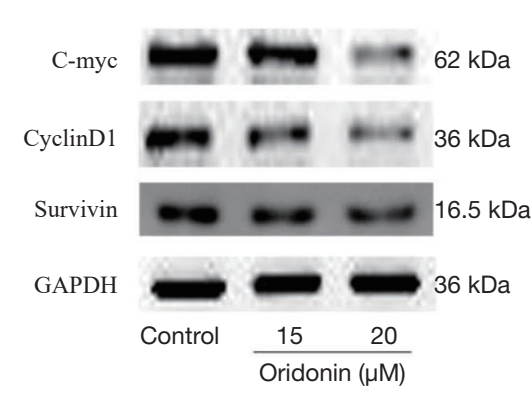

G

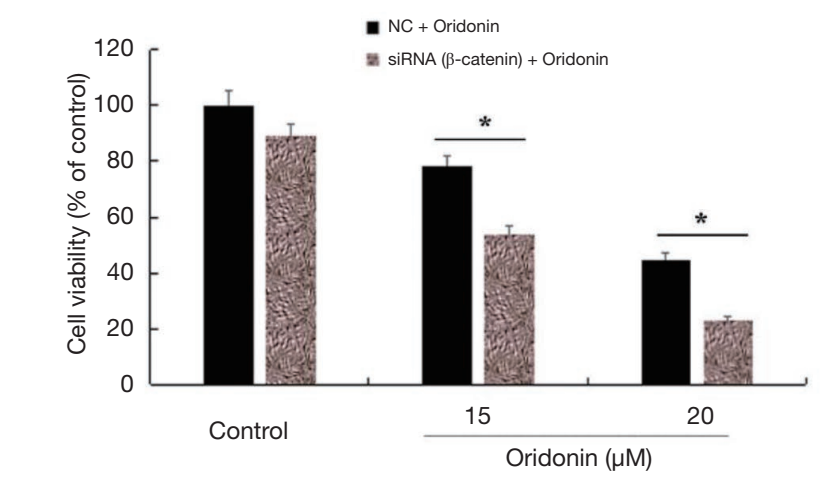

B

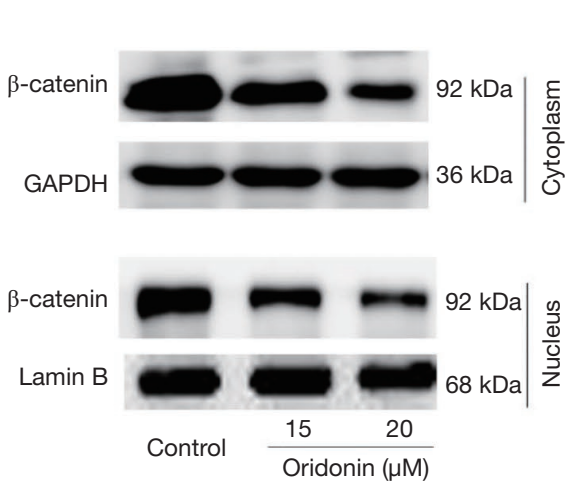

$E$

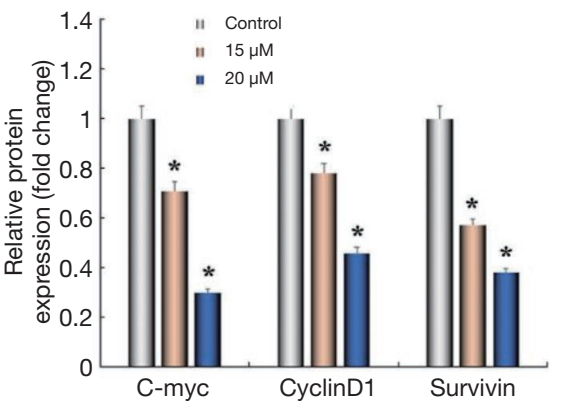

C

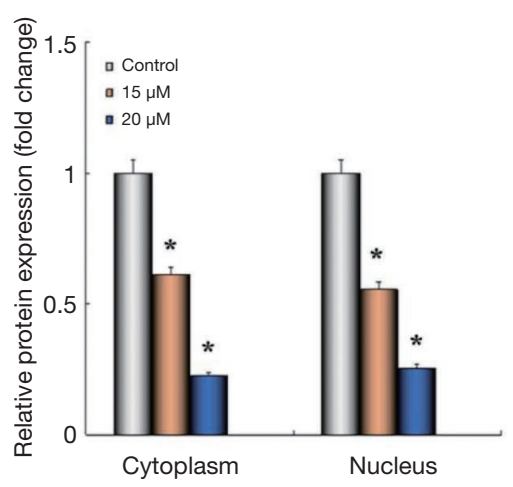

$\mathrm{F}$

Figure 3 Oridonin suppressed the expression of $\beta$-catenin and $W n t / \beta$-catenin targets in colon cancer cells. COLO205 cells were treated with oridonin $(0,15$ and $20 \mu \mathrm{M})$ for $48 \mathrm{~h}$. (A,B,C,D,E) Results of qPCR and western blotting analysis; (F,G) cells were transfected and exposed to oridonin for $48 \mathrm{~h}$. Protein expression levels of $\beta$-catenin and cleaved caspase- 3 were analysed by Western blotting. Cells viability was analysed by CCK-8 assay. ${ }^{*}, \mathrm{P}<0.05$ ( $v s$. the control). qPCR, quantitative polymerase chain reaction; CCK- 8 , Cell Counting Kit- 8 ; GAPDH, glyceraldehyde 3-phosphate dehydrogenase; siRNA, small interfering RNA; NC, normal control.

expression and down-regulation of $\beta$-catenin expression were all reversed in some degree. These data indicated that GSK3 $\beta / \beta$-catenin signaling pathway could be participated in oridonin-induced apoptosis in colon cancer COLO205 cells.

\section{Oridonin suppressed xenograft tumor growth}

To further explore the effect of oridonin on tumor growth in vivo, subcutaneous colon cancer COLO205 cell xenograft tumor model in nude mice was used. The experimental protocol was described in Figure 5 A. During the whole 
A

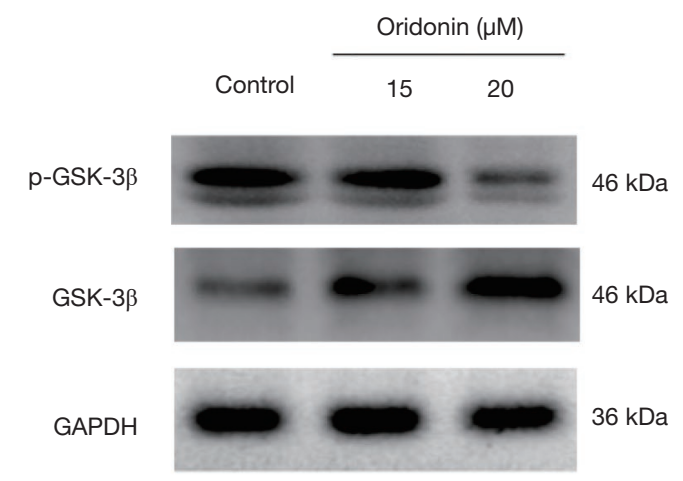

B

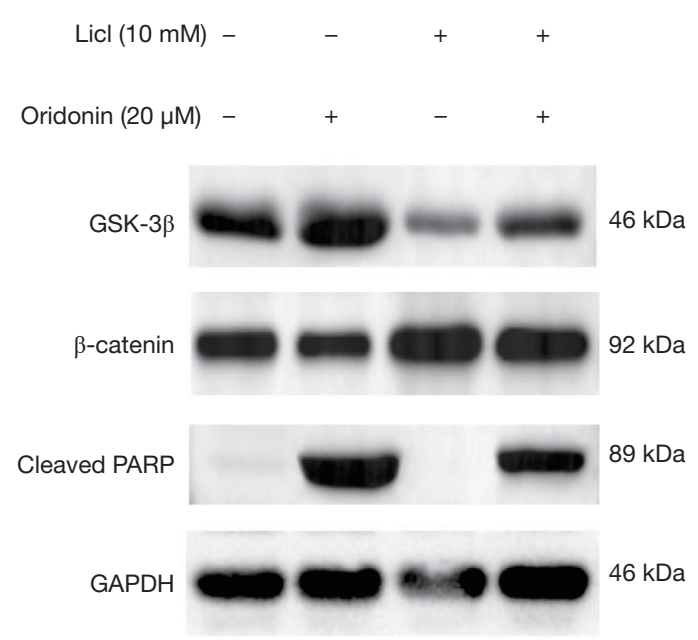

C

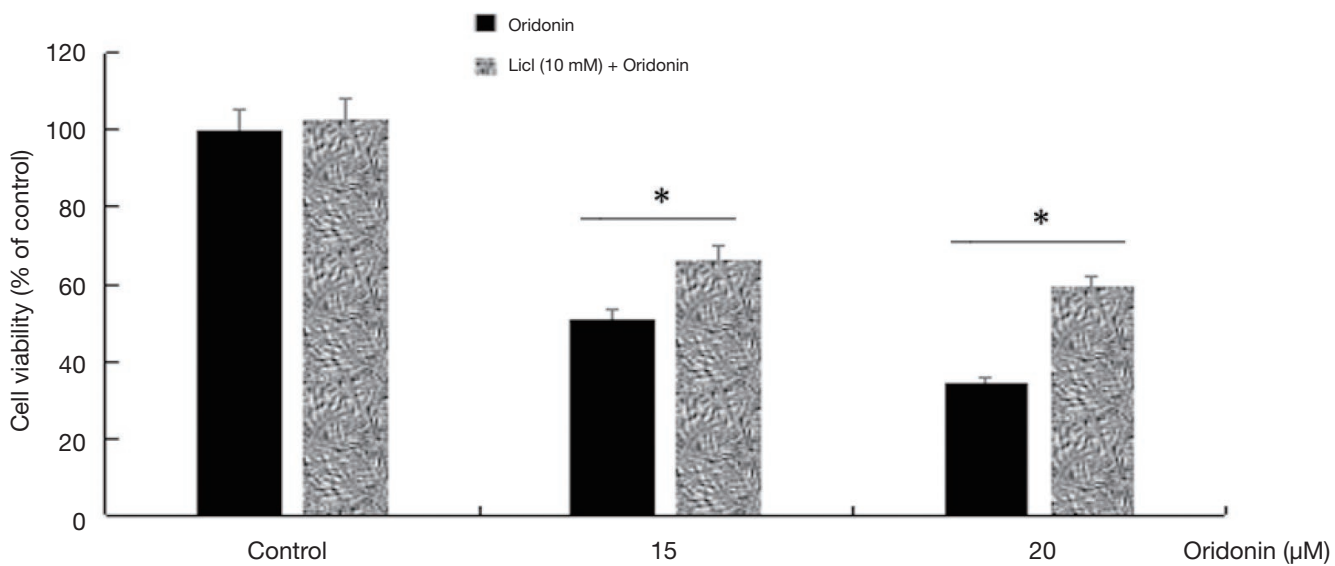

Figure 4 Oridonin suppressed the expression levels of $\beta$-catenin and downstream targets in colon cancer cells. (A) COLO205 cells were treated with oridonin $(0,15$ and $20 \mu \mathrm{M})$ for $48 \mathrm{~h}$. The protein expression of GSK3 $\beta$ and p-GSK3 $\beta$ were detected by Western blotting; (B) COLO205 cells were pretreated with $10 \mathrm{mM} \mathrm{LiCl}$ for $3 \mathrm{~h}$ and further treated with or without $20 \mu \mathrm{M}$ oridonin for $48 \mathrm{~h}$. The protein expression of GSK3 $\beta, \beta$-catenin and cleaved PARP were analysed by Western blotting; (C) cells viability was analysed by CCK-8 assay. *, P $<0.05$ ( $v s$. the control). GSK3 $\beta$, glycogen synthase kinase $3 \beta ; \mathrm{LiCl}$, lithium chloride; PARP, poly (ADP-ribose) polymerase; CCK-8, Cell Counting Kit-8; GAPDH, glyceraldehyde 3-phosphate dehydrogenase.

experiment, there was no statistically significant difference in the body weight in all groups when compared with the healthy mice (Figure 5B), suggesting that treatment of oridonin at the experimental concentrations would not cause significant systemic toxicity to the nude mice. However, After treatment with oridonin $(10,20 \mathrm{mg} / \mathrm{kg})$, there was a considerably higher reduction in tumor volume and tumor weight compared with the control group (Figure 5C,D), showing that COLO205 xenograft growth could be inhibited by oridonin. In order to further investigate the mechanism, TUNEL assay were conducted to analyze whether oridonin triggered tumor tissue apoptosis. As shown in Figure 5E,F, green fluorescence were apparently observed in oridonin-treated tumor tissue, suggesting oridonin could trigger apoptosis activation in COLO205 cell xenografts.

\section{Oridonin inbibited the expression of $\beta$-catenin, $c$-myc, cyclinD1 and survivin in tumor tissues}

To confirm whether oridonin exerted anti-tumor effects through regulating $\mathrm{Wnt} / \beta$-catenin pathway in vivo. Next, 
A Subcutaneous injection

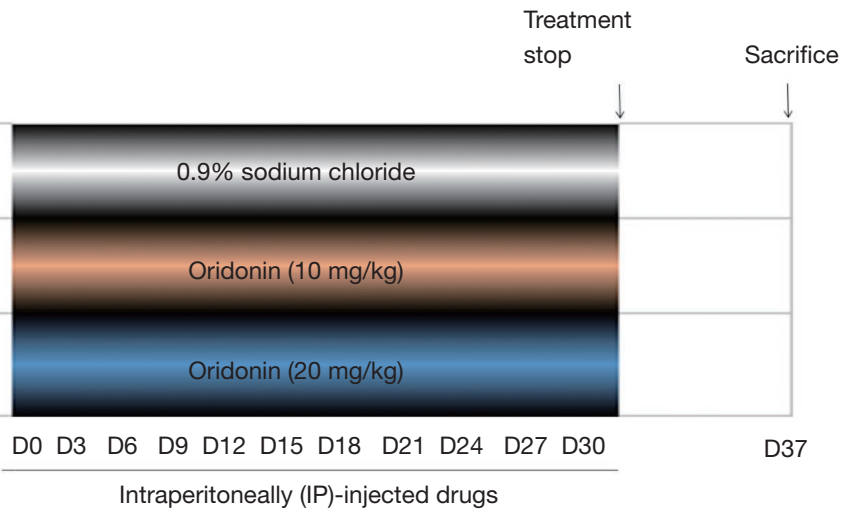

B

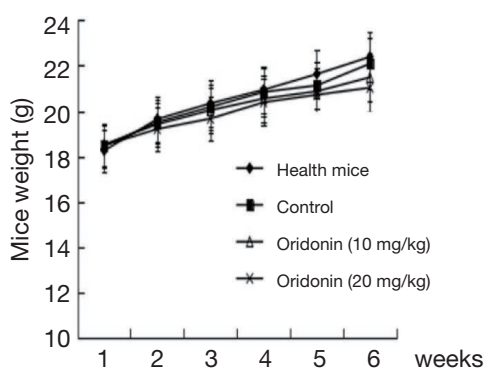

C

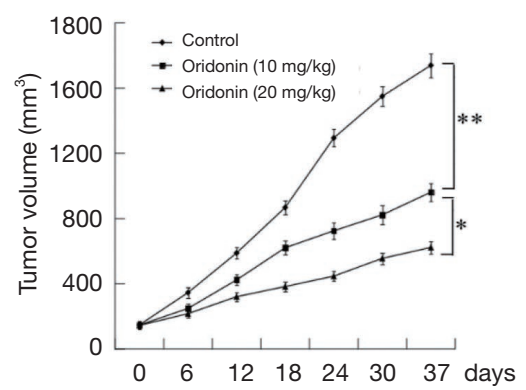

E

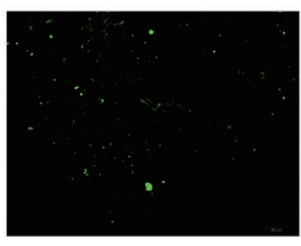

Control

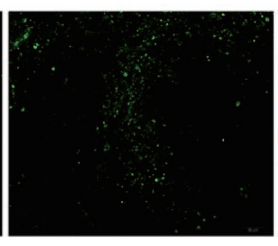

10

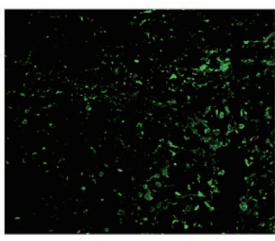

20
Oridonin $(\mathrm{mg} / \mathrm{kg})$

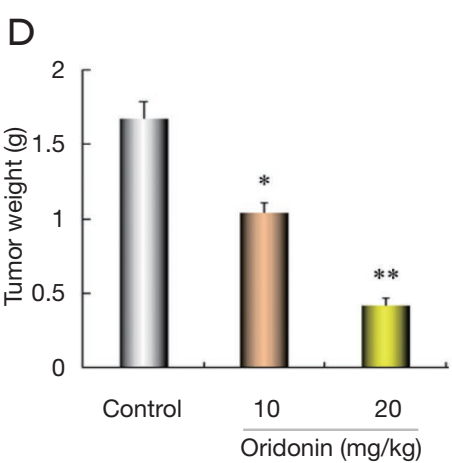

$\mathrm{F}$

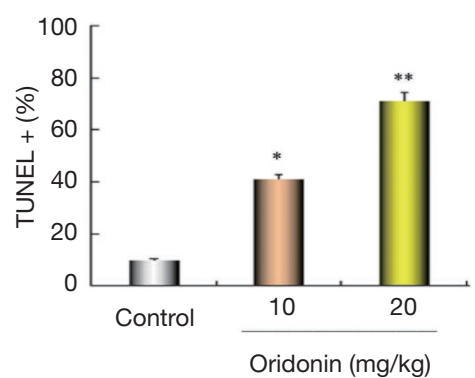

Figure 5 Oridonin inhibited COLO205 cell xenograft tumor growth. (A) The experimental protocol; (B,C) the mice body weight and tumor volume were measured; (D) one week after the last treatment, tumors were excised from the animals, and tumor weight of individual groups of mice was measured; (E) apoptotic cells in tumor sections were photographed in fluorescence microscope $(\times 400)$; $(\mathrm{F})$ relative percentage of apoptotic cells as shown in $\mathrm{E} .{ }^{*}, \mathrm{P}<0.05$ (vs. the control); ${ }^{* *}, \mathrm{P}<0.01$ (vs. the control). $\mathrm{D}$, days; IP, intraperitoneally.

the expression levels of $\beta$-catenin and $W n t / \beta$-catenin targets (c-myc, cyclinD1 and survivin) were determined in tumor tissues. qPCR analysis was further used to confirm that oridonin treatment significantly suppressed the mRNA expression levels of $\beta$-catenin, c-myc, cyclinD1 and survivin in tumor tissues; western blotting analysis also revealed a significant decrease of $\beta$-catenin, c-myc, cyclinD1 and survivin protein levels after oridonin treatment (Figure 6), which were in accordance with the data in vitro, indicating the inhibition of CRC growth and induction of apoptosis by oridonin may be partly through the inactivation of the $\mathrm{Wnt} / \beta$-catenin pathway in vivo.

\section{Discussion}

Nowadays, the incidence of CRC in Asian population is 
A

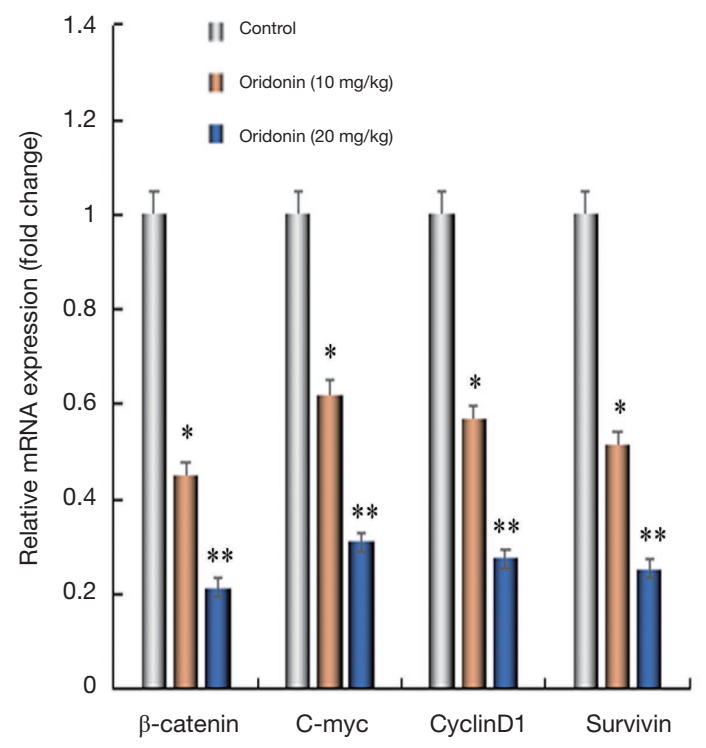

B

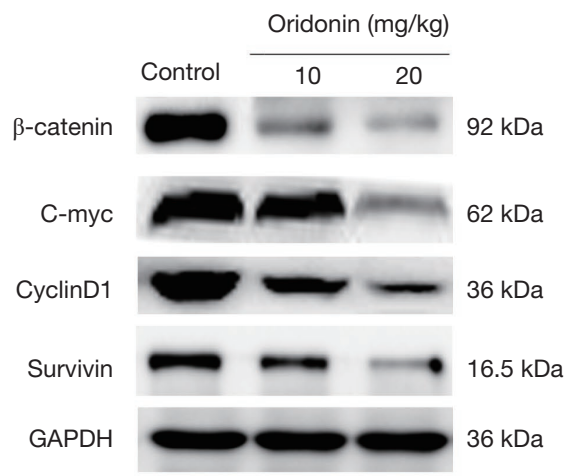

C

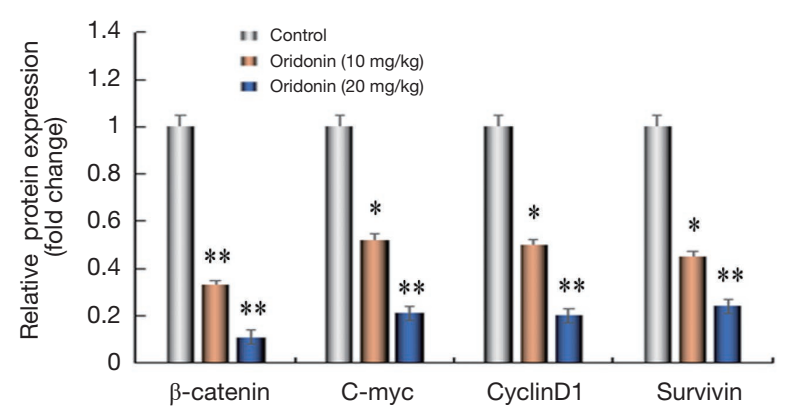

Figure 6 Effects of oridonin on the expression of $\beta$-catenin, c-myc, cyclinD1 and survivin in xenograft tumor tissues. (A) Results of qPCR analysis in tumor tissues; (B) results of western blotting analysis in tumor tissues; (C) quantified data from the western blotting. *, $\mathrm{P}<0.05$ (vs. the control); ** $\mathrm{P}<0.01$ (vs. the control). qPCR, quantitative polymerase chain reaction; GAPDH, glyceraldehyde 3-phosphate dehydrogenase.

growing rapidly, as a result of the popularity of the western diet. Although a series of targeted therapies have been developed to resist cancer (15-17), the severe side effects and drug resistance limit their application, and the curative effect on patients with CRC remains poor (18). Thus, novel therapeutic agents are urgently needed. The increasing acceptability of phytochemicals, as cancer chemopreventive agents in recent years may be attributed to their high potency, low toxicity and a relatively safe profile compared to synthetic anticancer agents. Previous research has proved that cytotoxic compounds in different plants could exert potential anticarcinogenic effects in a variety of cancer cells (19-22). Recently, the anticancer effect of oridonin has been the focus of many investigations. Previous reports have demonstrated that oridonin has the potential to treat CRC $(12,13)$. However, so far, there is no evidence to support the value of targeting $\mathrm{Wnt} / \beta$-catenin signaling in the treatment of CRC by oridonin. In our study, the data revealed that oridonin could effectively suppress the COLO205 cell proliferation and inhibit tumor growth in COLO205 cell xenografts through induction of apoptosis in vitro and in vivo. Furthermore, data suggested that the inhibitory effect of oridonin was achieved by blocking $\mathrm{Wnt} / \beta$-catenin signaling (GSK3 $\beta$ and $\beta$-catenin) and target genes (c-myc, cyclinD1 and survivin).

Apoptosis, commonly called programmed cell death, is a prominent hallmark of human cancers (23). Cleaved caspase- 3 is a critical mediator in cell apoptosis. When caspase- 3 is activated, it can cleave PARP to a specific $85-\mathrm{kDa}$ form, which is observed during apoptosis. In our investigation, we discovered that the expression levels of cleaved caspase- 3 and cleavage of PARP were markedly increased in COLO205 cells after treatment of oridonin, suggesting that apoptosis induced by oridonin in COLO205 cells was at least partly connected with activation of caspase-3.

Wnt/ $\beta$-catenin pathway was proved to be a critical target involved in the regulation of cell proliferation, differentiation and apoptosis induction, which correlated with occurrence, development and prognosis of tumors, including CRC (24). It plays indispensable role in the pathogenesis of CRC, and many drugs that target the 
$\beta$-catenin pathway potentially reduce the tumor growth (25-27). In the absence of Wnt signaling, AXIN, GSK3 $\beta$ and APC can aggregate as a complex which constitutively promotes the proteolytic degradation of $\beta$-catenin. Consequently, no $\beta$-catenin enters the nucleus and the relevant oncogenes are not activated. When the Wnt pathway is activated by carcinogenic factors, the binding of Wnt proteins to Frizzled receptors causes the accumulation of unphosphorylated $\beta$-catenin, which translocates into the nucleus and activates the transcription of c-myc, cyclinD1 and survivin, ultimately leading to proliferation and tumorigenesis (28). The proto-oncogenes cyclinD1 and c-myc act as a major role in cell proliferation, differentiation and apoptosis, and are correlated with the incidence of many tumors. CyclinD1 as a direct transcriptional Wnt signaling target participates in the regulation of cell proliferation and cell cycle progression (29). $\mathrm{C}$-myc has long been recognized as downstream target genes of $\mathrm{Wnt} / \beta$-catenin pathway activated by accumulated nucleus $\beta$-catenin binding with TCF/LEF through specific DNA binding sites. Survivin is a member of the inhibitor of apoptosis (IAP) family. The survivin protein functions to inhibit caspase activation, thereby leading to negative regulation of apoptosis or programmed cell death, which has been confirmed by disruption of survivin induction pathways leading to increase in apoptosis and decrease in tumour growth. Enlargement and tumorigenesis of CRC was strengthened through the expression of many genes including c-myc, CyclinD1 and survivin (30). Particularly, the plant products effectively inhibit the $\beta$-catenin expression and the tumor formation in CRC cells (31-33). Consistent with the previous findings, by analyzing the mRNA expression and protein expression levels of $\beta$-catenin and Wnt target genes, our results indicated that oridonin down-regulated $\beta$-catenin expression levels along with a reduced expression of c-myc, cyclinD1 and survivin, suggesting inhibition of this signalling pathway following treatment with oridonin. Moreover, both protein expression of $\beta$-catenin in cell nucleus and cytoplasm were significantly reduced, suggesting the transcription of $\beta$-catenin in CRC cells was inhibited by oridonin. In addition, after silencing $\beta$-catenin, inhibition of apoptosis-related protein and proliferation mediated by oridonin in COLO205 cells were obviously augmented. These findings showed that the antitumor activity of oridonin on colon cancer COLO205 cells could be mediated through deactivating the Wnt/ $\beta$-catenin pathway.

Evidences have proved that GSK3 $\beta$ acts as a dominant role in the degradation of complex and directly induces the phosphorylation level of $\beta$-catenin at Thr41, Ser37 and Ser33, finally resulting in subsequent proteasomal degradation (34). Proliferation and metastasis of multiple tumors are restrained by over-expression of GSK3 $\beta$ which suppresses $\beta$-catenin translocation into nucleus (35). Our data revealed that after treatment with oridonin, GSK3 $\beta$ was directly or indirectly targeted to down-regulate the expression level of $\beta$-catenin in cytoplasm and nucleus. While degradation of $\beta$-catenin and apoptosis induced by oridonin in COLO205 cells were partly suppressed by the specific inhibitor $(\mathrm{LiCl})$ of $\mathrm{GSK} 3 \beta$. As was consistent with previous reports that some anti-tumor agents weakened the expression level of $\mathrm{p}-\mathrm{GSK} 3 \beta$ to promote degradation of $\beta$-catenin in CRC cells, simultaneously the levels of GSK3 $\beta$ were strengthened (36-38). Taken together, oridonin effectively heightened stability of GSK $3 \beta$, decreased the level of $\beta$-catenin and the expression of oncogene to perform a function in the prevention of CRC.

As the anti-tumor effect of oridonin on COLO205 cells has been certified, we further confirmed whether oridonin could suppress the growth of COLO205 cells xenografted tumor in nude mice. The results showed that the average volume and weight of the finally resected tumors were significantly decreased by oridonin. Additionally, TUNEL assay indicated that oridonin could trigger cell apoptosis in tumor tissue. Furthermore, the expression of $\beta$-catenin and target genes (cyclinD1, c-myc and survivin) in tumor tissue were observably down-regulated according to the results of the western blotting and qPCR assay. Overall, these results confirmed that oridonin inhibited the growth of COLO205 cell xenograft and induced apoptosis by restraining the $\mathrm{Wnt} / \beta$-catenin pathway in vivo.

In summary, our findings indicated that oridonin repressed the growth of colon cancer cells and induced apoptosis in vitro and in vivo. The changes in Wnt pathways-related transcripts and proteins suggest that oridonin-mediated regulation involves canonical Wnt/ GSK3 $\beta / \beta$-catenin pathway, which contributes to controlling proliferation in colon tumors. Our results provided valuable evidences to support oridonin as a potential agent for the preventive role in CRC.

\section{Acknowledgments}

The authors would like to thank the Animal Experimental Research Center in Zhejiang Chinese Medical University for technical assistance. 
Funding: This study was supported by Medical Health Science and Technology Project of Zhejiang Province Health Commission (Grant No. 2018KY325) and The Natural Science Foundation of Zhejiang Province (Grant No. Y17H160187).

\section{Footnote}

Conflicts of Interest: All authors have completed the ICMJE uniform disclosure form (available at http://dx.doi. org/10.21037/tcr.2019.08.25). The authors have no conflicts of interest to declare.

Ethical Statement: The authors are accountable for all aspects of the work in ensuring that questions related to the accuracy or integrity of any part of the work are appropriately investigated and resolved. All experimental procedures and protocols were approved by the Institutional Animal Care and Use Committee of the Zhejiang Chinese Medical University (No. 2018-0012).

Open Access Statement: This is an Open Access article distributed in accordance with the Creative Commons Attribution-NonCommercial-NoDerivs 4.0 International License (CC BY-NC-ND 4.0), which permits the noncommercial replication and distribution of the article with the strict proviso that no changes or edits are made and the original work is properly cited (including links to both the formal publication through the relevant DOI and the license). See: https://creativecommons.org/licenses/by-nc-nd/4.0/.

\section{References}

1. Siegel RL, Miller KD, Jemal A. Cancer statistics, 2016. CA Cancer J Clin 2016;66:7-30.

2. Pan R, Zhu M, Yu C, et al. Cancer incidence and mortality: a cohort study in China, 2008-2013. Int J Cancer 2017;141:1315-23.

3. Choi Y, Sateia HF, Peairs KS, et al. Screening for colorectal cancer. Semin Oncol 2017;44:34-44.

4. Donovan MG, Selmin OI, Doetschman TC, et al. Mediterranean diet: prevention of colorectal cancer. Front Nutr 2017;4:59.

5. Deitrick J, Pruitt WM. Wnt/ $\beta$ catenin-mediated signaling commonly altered in colorectal cancer. Prog Mol Biol Transl Sci 2016;144:49-68.

6. Bourroul GM, Fragoso HJ, Gomes JW, et al. The destruction complex of beta-catenin in colorectal carcinoma and colonic adenoma. Einstein (Sao Paulo) 2016;14:135-42.

7. Bahrami A, Amerizadeh F, ShahidSales S, et al. Therapeutic potential of targeting $\mathrm{Wnt} / \beta$-catenin pathway in treatment of colorectal cancer: rational and progress. J Cell Biochem 2017;118:1979-83.

8. Shang $\mathrm{S}, \mathrm{Hua} F, \mathrm{Hu} Z \mathrm{ZW}$. The regulation of $\beta$-catenin activity and function in cancer: therapeutic opportunities. Oncotarget 2017;8:33972-89.

9. $\mathrm{Xu}$ J, Wold EA, Ding Y, et al. Therapeutic potential of oridonin and its analogs: from anticancer and antiinflammation to neuroprotection. Molecules 2018. doi: 10.3390/molecules23020474.

10. Liu Y, Liu YZ, Zhang RX, et al. Oridonin inhibits the proliferation of human osteosarcoma cells by suppressing Wnt/ $\beta$-catenin signaling. Int J Oncol 2014;45:795-803.

11. Liang J, Wang W, Wei L, et al. Oridonin inhibits growth and induces apoptosis of human neurocytoma cells via the Wnt//-catenin pathway. Oncol Lett 2018;16:3333-40.

12. Liu RX, Ma Y, Hu XL, et al. Anticancer effects of oridonin on colon cancer are mediated via BMP7/p38 MAPK/p53 signaling. Int J Oncol 2018;53:2091-01.

13. Wu QX, Yuan SX, Ren CM, et al. Oridonin upregulates PTEN through activating p38 MAPK and inhibits proliferation in human colon cancer cells. Oncol Rep 2016;35:3341-8.

14. He F, Chen H, Yang P, et al. Gankyrin sustains PI3K/ GSK-3 $\beta / \beta$-catenin signal activation and promotes colorectal cancer aggressiveness and progression. Oncotarget 2016;7:81156-71.

15. Zheng X, Liu G, Cui G, et al. Angiotensin-converting enzyme gene deletion polymorphism is associated with lymph node metastasis in colorectal cancer patients in a chinese population. Med Sci Monit 2017;23:4926-31.

16. Sun $X$, Yuan W, Hao F, et al. Promoter methylation of rassf1a indicates prognosis for patients with stage II and III colorectal cancer treated with oxaliplatin-based chemotherapy. Med Sci Monit 2017;23:5389-95.

17. Wang $\mathrm{T}, \mathrm{Xu} \mathrm{H}$, Liu $\mathrm{X}$, et al. Identification of key genes in colorectal cancer regulated by miR-34a. Med Sci Monit 2017;23:5735-43.

18. Day LW, Velayos F. Colorectal cancer screening and surveillance in the elderly: updates and controversies. Gut Liver 2015;9:143-51.

19. Wu X, Song M, Gao Z, et al. Nobiletin and its colonic metabolites suppress colitis-associated colon carcinogenesis by down-regulating iNOS, inducing antioxidative enzymes and arresting cell cycle progression. J Nutr Biochem 
2017;42:17-25.

20. Xu DP, Zheng J, Zhou Y, et al. Extraction of natural antioxidants from the thelephora ganbajun mushroom by an ultrasound-assisted extraction technique and evaluation of antiproliferative activity of the extract against human cancer cells. Int J Mol Sci 2016. doi: 10.3390/ ijms17101664.

21. Shiau JY, Nakagawa-Goto K, Lee KH, et al. Phytoagent deoxyelephantopin derivative inhibits triple negative breast cancer cell activity by inducing oxidative stress-mediated paraptosis-like cell death. Oncotarget 2017;8:56942-58.

22. Yadav NK, Arya RK, Dev K, et al. Alcoholic extract of eclipta alba shows in vitro antioxidant and anticancer activity without exhibiting toxicological effects. Oxid Med Cell Longev 2017;2017:9094641.

23. Abraha AM, Ketema EB. Apoptotic pathways as a therapeutic target for colorectal cancer treatment. World J Gastrointest Oncol 2016;8:583-91.

24. Krishnamurthy N, Kurzrock R. Targeting the Wnt/ beta-catenin pathway in cancer: update on effectors and inhibitors. Cancer Treat Rev 2018;62:50-60.

25. Egashira I, Takahashi-Yanaga F, Nishida R, et al. Celecoxib and 2,5-dimethylcelecoxib inhibit intestinal cancer growth by suppressing the $\mathrm{Wnt} / \beta$-catenin signaling pathway. Cancer Sci 2017;108:108-15.

26. Reddivari L, Charepalli V, Radhakrishnan S, et al. Grape compounds suppress colon cancer stem cells in vitro and in a rodent model of colon carcinogenesis. BMC Complement Altern Med 2016;16:278.

27. Manigandan K, Manimaran D, Jayaraj RL, et al. Taxifolin curbs NF- $\mathrm{\kappa B}$-mediated $\mathrm{Wnt} / \beta$-catenin signaling via up-regulating Nrf2 pathway in experimental colon carcinogenesis. Biochimie 2015;119:103-12.

28. Kong LM, Feng T, Wang YY, et al. Bisleuconothine $\mathrm{A}$, a bisindole alkaloid, inhibits colorectal cancer cell in vitro and in vivo targeting $\mathrm{Wnt}$ signaling. Oncotarget 2016;7:10203-14.

Cite this article as: $\mathrm{Bu} \mathrm{H}$, Liu D, Cui J, Cai K, Shen F. $\mathrm{Wnt} / \beta$-catenin signaling pathway is involved in induction of apoptosis by oridonin in colon cancer COLO205 cells. Transl Cancer Res 2019;8(5):1782-1794. doi: 10.21037/tcr.2019.08.25
29. Chen HJ, Hsu LS, Shia YT, et al. The $\beta$-catenin/TCF complex as a novel target of resveratrol in the $\mathrm{Wnt} /$ $\beta$-catenin signaling pathway. Biochem Pharmacol 2012;84:1143-53.

30. Wu G, Yuan M, Shen S, et al. Author correction: menin enhances c-Myc-mediated transcription to promote cancer progression. Nat Commun 2018;9:16195.

31. Gu J, Cui CF, Yang L, et al. Emodin inhibits colon cancer cell invasion and migration by suppressing epithelialmesenchymal transition via the $\mathrm{Wnt} / \beta$-catenin pathway. Oncol Res 2019;27:193-202.

32. Dou H, Shen R, Tao J, et al. Curcumin suppresses the colon cancer proliferation by inhibiting $\mathrm{Wnt} / \beta$-catenin pathways via miR-130a. Front Pharmacol 2017;8:877.

33. Kim WK, Bach DH, Ryu HW, et al. Cytotoxic activities of Telectadium dongnaiense and its constituents by inhibition of the $\mathrm{Wnt} / \beta$-catenin signaling pathway. Phytomedicine 2017;34:136-42.

34. McCubrey JA, Davis NM, Abrams SL, et al. Diverse roles of GSK-3: tumor promoter-tumor suppressor, target in cancer therapy. Adv Biol Regul 2014;54:176-96.

35. Li XG, Wang $Z$, Chen RQ, et al. LGR5 and BMI1 increase pig intestinal epithelial cell proliferation by stimulating Wnt/ß-catenin signaling. Int J Mol Sci 2018. doi: 10.3390/ijms19041036.

36. Zhuang YW, Wu CE, Zhou JY, et al. Solasodine inhibits human colorectal cancer cells through suppression of the AKT/glycogen synthase kinase-3 $\beta / \beta$-catenin pathway. Cancer Sci 2017;108:2248-64.

37. Yu W, Liu C, Li X, et al. Inositol hexaphosphate suppresses colorectal cancer cell proliferation via the Akt/GSK-3 $3 /$ $\beta$-catenin signaling cascade in a 1,2-dimethylhydrazineinduced rat model. Eur J Pharmacol 2017;805:67-74.

38. Wang G, Feng CC, Chu SJ, et al. Toosendanin inhibits growth and induces apoptosis in colorectal cancer cells through suppression of AKT/GSK-3 $\beta / \beta$-catenin pathway. Int J Oncol 2015;47:1767-74. 